\title{
«OTROS» ENTRE «NOSOTROS»: LA CONFLICTIVA MIRADA DEL COLONIZADOR GOLONIZADO EN BWANA
}

\author{
Raquel Vega-Durán
}

Claremont McKenna College

Basada en la obra de teatro de Ignacio del Moral La mirada del hombre oscuro, la película Bwana (Imanol Uribe, 1996) narra la historia del encuentro entre una familia española formada por José Antonio (el padre), Dori (la madre), Iván (el hijo) y Jessi (la hija), con un inmigrante subsahariano llamado Ombasi ${ }^{1}$ (y su amigo ahogado) y un grupo de neonazis (dos hombres y una mujer). La acción tiene lugar en una playa del sur de España donde la familia está buscando coquinas. Para evitar que le roben el coche, José Antonio decide llevarse una bujía, objeto que pierde, por lo que tienen que permanecer en la playa hasta que aparece al día siguiente. Durante este tiempo se encuentran todos los personajes. La historia, con un final dramático, se ve rodeada de la violencia entre los neonazis y la familia y el rechazo de todos ellos hacia Ombasi. Los intentos de Ombasi de acercarse a la familia no tienen éxito y la película nos deja un final abierto con la imagen de la familia huyendo en su coche mientras Ombasi yace en el camino por el que se acercan los neonazis. Según cuenta el propio Uribe en el artículo «Teníamos nuestros miedos antes del rodaje», publicado en El País,

Bwana es quizás la película que sobre el papel más me ha costado arrancar y estaba asustado porque no había red; son únicamente once personajes en tres actos muy delimitados, casi teatrales, la tarde, la noche y el amanecer, en un mismo decorado desierto y sin nada a lo que agarrarse o mirar. Fue una suerte poder hacerla por orden, algo que es muy raro en el cine, porque me ha permitido que se puedan ir incorporando cosas y elementos nuevos que enriquecían la historia (García, 1996).

1 En la obra de teatro La mirada del hombre oscuro el inmigrante con el que se encuentra la familia se llama Ombasi, el mismo nombre que tiene el inmigrante en Bwana. Sin embargo, aunque este último (interpretado por el actor Emilio Buale) repetirá su nombre en varios momentos de la película, ni los personajes ni el espectador percibirán «Ombasi» como su nombre al no entender el lenguaje del inmigrante, hecho que enfatiza la continua incomunicación que tiene lugar en Bwana. Por razones de claridad, en este artículo se usará el nombre de Ombasi en referencia al inmigrante. 
Existen varios estudios sobre la película que analizan principalmente el racismo procedente de la familia española y los neonazis hacia el inmigrante y cómo se le convierte en "otro» por medio de este racismo ${ }^{2}$. Sin embargo, este estudio pretende ofrecer una nueva perspectiva. La familia española, desde el primer momento que entra en contacto con el inmigrante, reproduce el imaginario colonial, utilizando una mirada orientalista para mostrar a África como inversión de Europa. Sin embargo, aunque a primera vista Bwana parece enfocarse en la presencia de la otredad africana en España, a medida que transcurre la historia el espectador percibe que el inmigrante funciona como elemento que facilita el estudio del propio español, convirtiendo a este último en foco de atención. Así, si bien la película parece seguir la lógica simplista del paradigma tradicional racista de construcción de otredad al examinar cómo los personajes de raza blanca intentan definir a aquel de raza negra como inferior, esta lógica se fractura tras un análisis de las propias acciones y retórica de la familia, dando como resultado la inversión del binomio tradicional sujeto/objeto. Bwana coloca al español como objeto de estudio y espectáculo, mostrando cómo el agente de un discurso racista se convierte en objeto de su propia retórica llegando incluso a despertar la reflexión del público español sobre sí mismo.

Los encuentros entre los grupos en Bwana se producen en lo que Mary Louise Pratt ha denominado «contact zones»,

social spaces where disparate cultures meet, clash, and grapple with each other, often in highly asymmetrical relations of domination and subordination - like colonialism, slavery, or their aftermaths as they are lived out across the globe today (1992: 4).

En Bwana una playa andaluza se transforma en zona de contacto entre Europa y África donde, por una parte, los neonazis intentan situarse como superiores tanto de los españoles como del inmigrante $y$, por otra, los españoles se empeñan en definir al inmigrante como inferior. Sin embargo, durante la película este triángulo se invierte. Aunque esta zona de contacto, frontera entre las dos orillas del Mediterráneo, es a su vez zona de encuentros y desencuentros, desde un primer momento la familia se decanta por el aspecto de separación, estableciendo una clara diferencia entre un nosotros español y un ellos africano para reforzar su posición como superiores y mostrar que el "otro" es inadmisible dentro de su territorio. Sin embargo, es el inmigrante, percibido como primitivo por parte tanto de los neonazis como de la familia, el que trastoca este patrón y se coloca como agente civilizador. Bwana logra invertir el discurso tradicional racista al mostrar cómo los sujetos que en apariencia se presentan como superiores revelan su propio lado primitivo con su propio comportamiento.

2 Véanse por ejemplo Cine (in)surgente: Textos fílmicos y contextos culturales de la España postfranquista (Isolina Ballesteros, 2001), Los «Otros». Etnicidad y «raza» en el cine español contemporáneo (Isabel Santaolalla, 2005), La memoria escondida. Emigración y cine (Eduardo Moyano, 2005) o el capítulo de Olga López Cotín «Desde la mirada oscura: geografías fílmicas de la inmigración en España» (en Memoria colonial e inmigración: La negritud en la España posfranquista, 2007), entre otros. El estreno de Bwana propició también la aparición de numerosas reseñas y críticas. Un listado de éstas recopilado por Igor Barrenetxea Marañón se puede encontrar en $<$ http://www.fsancho-sabio.es/html/peliculas1.html $>$. 


\section{UN INFUNDADO IMAGINARIO COLONIAL}

Desde el primer momento que la familia entra en contacto con Ombasi se reproduce el imaginario colonial. Así, al sujeto de raza negra le atribuyen las características de «infantilismo, animalización, canibalismo, falta de higiene y exoticismo» (Ballesteros, 2001: 223). La madre, Dori, es la principal fuente de información para sus hijos, adoptando desde un primer momento una mirada orientalista sobre el sujeto extranjero donde resalta un racismo de estilo colonial. La madre no sólo ofrece una visión colonial de Ombasi sino que respalda y confirma cada uno de los comentarios racistas de sus hijos, «educándolos» y reforzando así la retórica de la siguiente generación. Por otra parte, si bien el padre cuestiona y ridiculiza los comentarios de su mujer, nunca los llega a rebatir con argumentos convincentes, por lo que la mirada colonial llega finalmente a ser compartida por toda la familia.

Los frecuentes comentarios de Dori siguen con precisión los siguientes mecanismos:

Within the transformational grammar of colonial-style racism, several key mechanisms stand out: (1) the positioning of lack; that is, the projection of the racially stigmatized as deficient in terms of European norms, as lacking in order, intelligence, sexual modesty, material civilization, even history [...]. Racism also involves (2) the mania of hierarchy, for ranking not only peoples [...] but also artifacts and cultural practices [...]. Racism also entails the interrelated processes of (3) blaming the victim and (4) the refusal of empathy [...]. Racism involves (5) the systematic devalorization of life, which sometimes takes the extreme form of open calls for murder (Shohat y Stam, 1994: 23).

Durante la película, Dori se empeña en definir a Ombasi como (1) sujeto carente de cultura e historia; (2) insiste en el establecimiento de una jerarquía (situándose siempre por encima de Ombasi); (3) retrata a la víctima como culpable; (4) rechaza la identificación con el «otro»; y (5) desvaloriza la vida del inmigrante africano al definirlo como animal y canibal. Por medio de múltiples «lecciones», de las que solo examinaré una selección, la madre reproduce el imaginario colonial racista retratando al inmigrante como el típico elemento sacado de las postales «Scènes et types» del periodo colonial que representaban al colonizado como un objeto no civilizado carente de todo aquello que significaba ser europeo.

Lo primero que destaca entre los comentarios de Dori es su énfasis en la carencia de cultura e historia de Ombasi:

Hija: Mamá, ¿por qué siempre dice [Ombasi] lo mismo?

Madre: Porque a lo mejor no sabe decir otra cosa.

Hija: ¿No sabe hablar más?

Madre: No hija, no, estas personas negras son muy incultas.

La hija se refiere a las únicas palabras que Ombasi pronuncia en español al intentar establecer comunicación con la familia: «iViva España!» e «Indurain». Si bien Ombasi las repite en varias ocasiones para procurar un acercamiento hacia el sujeto español, esto solo lo consigue la primera vez, y aún entonces solo despertará una pequeña curiosidad que desaparecerá al instante. Su intento de relacionarse con el español usando su idioma se verá frustrado ya que, como puede desprenderse de la conversación, el uso del español por parte de Ombasi no 
se ve como un conocimiento que posee el extranjero, sino como una carencia. Franz Fanon examina este aspecto en Peau noire, masques blancs:

Je rencontre un Allemand ou un Russe parlant mal le français. Par gestes, j'essaie de lui donner le renseignement qu'il réclame, mais ce faisant, je n'ai garde d'oublier qu'il a une langue propre, un pays, et qu'il est peut-être avocat ou ingénieur dans sa culture. En tout cas, il est étranger à mon groupe, et ses normes doivent être différentes.

Dans le cas du Noir, rien de pareil. II n's pas de culture, pas de civilisation, pas ce "long passé d'historie" (1952: 26-27).

Así, las palabras en español que articula Ombasi no las toman como un intento del extranjero de establecer un diálogo en un idioma diferente del suyo, esto es, diferente a un idioma que domina. Su impuesta condición de inferior implica una carencia de todo lo considerado civilizado —ya que sólo sabe dos palabras (en español)_ una carencia que lo define, de una forma eurocéntrica, como un ser sin cultura ni civilización. A su vez, al percibir a Ombasi como carente de un lenguaje propio, Dori lo sitúa como inferior, estableciendo con ello una jerarquía continuadora del discurso renaniano y hegeliano en el que se percibe a «Africa very much as a kind of inversion of Europe» (Jahoda, 1999: 113-114).

El tercer mecanismo de alteridad usado por la familia es la presentación de la víctima como culpable:

Madre: ¿Para qué habrá venido?

Padre: Cualquiera sabe, a buscar trabajo.

Madre: Pues ya ves tú, ¡como que aquí no hay paro! Al final terminará metido en la droga como todos, lo estoy viendo. En cuanto veamos a la Guardia Civil hay que decírselo.

Esta escueta conversación presenta la «culpabilidad» del inmigrante desde uno de los focos más comúnmente usados como justificación de su rechazo: su contribución al aumento del paro en la sociedad de acogida y el perjuicio que su presencia traerá al país con las drogas. Con estas palabras, la madre reproduce el estereotipo del inmigrante como sujeto dañino y perjudicial para el «Norte».

Esta característica de culpabilidad también aparece en términos de salud. Al anochecer, mientras la familia se reúne en torno a una hoguera encendida por Ombasi, el padre acepta una de las coquinas que Ombasi le ofrece, mas las palabras de Dori le hacen escupir el molusco:

Madre: Estos negros están llenos de microbios, José Antonio, lo dicen todos los días en la tele.

Padre: Joder ya me has contagiado la aprensión.

A Ombasi se le percibe como culpable potencial de transmitir enfermedades a los miembros del país de acogida y esta afirmación de la madre se ve reforzada por la «verdad» que transmite la televisión, un medio en el que sigue predominando una percepción poco positiva de la inmigración. Éste es un momento significativo en la interacción entre la familia española y Ombasi. Hasta el momento José Antonio ha dejado claro que no comparte los comentarios racistas de la madre, aunque sus respuestas se han limitado a simples "iQué tonterías le 
dices a la niña!», opinión que repite varias veces. Sin embargo, a partir de ahora, tras haberle «contagiado la aprensión», José Antonio se posiciona del lado de su mujer. Así, tras escuchar a Dori hablar de las enfermedades que puede transmitir Ombasi y escupir la coquina, José Antonio deja clara la separación y su rechazo hacia el sujeto foráneo.

El cuarto mecanismo de la retórica racista que aparece es la negativa a la identificación, evidente en la homogeneidad que se le impone a Ombasi:

Madre: ¿De dónde vendrá?

Padre: ¡Y yo qué sé! De África.

Con esta afirmación, el padre simplifica el origen de Ombasi, definiéndolo como procedente de un lugar homogéneo y opuesto al suyo. Así, su retórica fluye de forma paralela al espacio fronterizo en el que se encuentran, una playa convertida en barrera diferenciadora de las dos orillas.

Un último elemento de la retórica racista de la familia es su desvalorización de la vida del «otro» con el uso de varios mecanismos mediante los que desprecian al imigrante al definirlo como primitivo, animal, y hasta canibal. Por ejemplo, al acercarse el inmigrante a la familia, el padre lo aleja con el rastrillo que había estado usando para buscar coquinas diciéndole, a la manera que se habla a un perro: «iNo te muevas! ¡Lárgate! [y dirigiéndose a su familia] Tranquilos, como vea que tengamos miedo es peor». Aunque para el espectador queda claro que Ombasi solo pretende acercarse a la familia para poder establecer comunicación, las palabras de José Antonio dan a entender que más que tratar con una persona parecen estar haciéndolo con un animal que les atacará si percibe cierto nerviosismo en sus «víctimas».

Otro ejemplo lo tenemos en los comentarios que se intercambian entre madre e hija:

Hija: Mamá, [Ombasi] tiene unos dientes muy grandes.

Madre: Sí, porque viene de la selva y aquello está lleno de fieras.

La idea de «animalidad» del africano es uno de los conceptos que ha sobrevivido con más fuerza en el discurso racista. Con estas palabras, Dori reproduce las palabras de Leo Africanus anotadas en su History and Description of Africa del siglo XVI:

The Negroes leade a beastly kinde of life, being utterly destitute of the use of reason, dexteritie or wit, and of all artes. Yea they do so behave themselves as if they had continually lived in a forest among wilde beasts. They have great swarmes of harlots among them; whereupon a man might easily conjecture their manner of living (citado en Jahoda, 1999: 30).

A la manera de Leo Africanus, el énfasis en el tamaño de los dientes de Ombasi lo sitúa «entre las bestias salvajes». Este comentario anticipa a su vez la percepción de Ombasi como canibal, una identidad que junto con la de animalidad «are the most ancient, most enduring, and carry the heaviest emotional load; they are at the exotic extreme of 'otherness'» (Jahoda, 1999: xv). Esta percepción del inmigrante como canibal la encontramos en la escena que reúne a la familia alrededor del fuego hecho por Ombasi: 
Hijo: ¿Dónde está el muerto que había aquí contigo?

[Ombasi le hace una señal de invitación para comer coquinas]

Hija: ¡Se ha comido al otro negro! [...] ¿Y si me come?

Madre: No te come hija, es bueno.

Hija: No, es malo, se come a otros.

Madre: Bueno, pero ahora no tiene hambre.

La idea de canibalismo se utiliza como un signo de su «bestialidad» y lo emplaza en el «extremo exótico» de la otredad (Jahoda, 1999: xv). Esta idea ilumina y subraya la separación entre la familia (o «lo civilizado») y el salvaje (en este caso, el africano), imposibilitando cualquier posible acercamiento debido a su insuperable diferencia.

\section{DE SUJETO A OBJETO, O CÓMO EL COLONIZADOR SE CONVIERTE EN COLONIZADO}

Bwana tiene como protagonistas a tres grupos que parecen ajustarse a estereotipos claramente definidos. Por una parte nos encontramos a los neonazis, un grupo de ideología activamente racista y al que desde un primer momento el público rechazará. Por otra parte, está el inmigrante «sin nombre» (Ombasi), un personaje que sufre discriminación e incomunicación. Sin embargo, la falta de referencia a su origen e identidad imposibilita la identificación del espectador con él (aun cuando su comportamiento pacífico y dialogante es el más cercano a la idea de civilización del público). Un tercer grupo lo forma la familia, del mismo origen que el espectador meta, a la que le toma por sorpresa la presencia del inmigrante africano, una sorpresa que les hace sentirse incómodos y les lleva a querer volver a su vida anterior al encuentro.

Isolina Ballesteros, en su libro Cine (in)surgente examina esta película y concluye que:

se culpa del racismo extremo y activo a los otros, grupos organizados y violentos (también extranjeros), frente a los cuales las actitudes de los españoles serían fácilmente comprensibles: un mal menor que no pasa de la estupidez e incluso una legítima defensa (2001: 228).

En este artículo me gustaría sugerir una interpretación diferente, examinando cómo hay ciertas instancias de la película que hacen que sea difícil que los espectadores de Bwana compartan y comprendan la visión de la familia. Por una parte el público tiene un conocimiento más amplio que la familia sobre Ombasi; por otra parte, la extrema simplicidad de los miembros de la familia, el uso de un discurso racista sin fundamentos y la agresividad verbal y física que existe entre ellos no facilita la identificación con estos sujetos; por último, la escena final de la película muestra al público cómo el activo rechazo de la familia hacia un "otro» facilita la muerte de Ombasi, dificultando toda posible empatía con ellos. Además, si durante la película hemos sido espectadores pasivos ante la tragedia, la mirada de Ombasi hacia la cámara en esta escena convierte al espectador en sujeto activo que llegará a cuestionarse su propia identidad.

Por una parte, el espectador tiene una perspectiva de Ombasi diferente de la familia, ya que el público tiene acceso a subtítulos que traducen lo que Ombasi está diciendo cuando la familia no está presente, con lo que llegamos a conocer un poco de su pasado y las ra- 
zones por las que vino. (En las escenas que Ombasi comparte con la familia sus palabras no se traducen, enfatizando con ello la incomprensión entre los personajes). Otra instancia del conocimiento privilegiado del espectador de Ombasi aparece con el cuerpo muerto de su amigo, al que tras su muerte por ahogamiento Ombasi entierra bajo la arena. Seguidamente, al tropezarse Antonio con lo que él cree ser una pequeña duna, Ombasi le grita. Al igual que ha hecho a lo largo de la película, la familia no siente curiosidad por esta reacción, asumiendo que es un comportamiento irracional del «animal» con el que están tratando. Por su parte el público, que sabe que la «duna» es la tumba del ahogado, no cuestiona la reacción de Ombasi, sino que la apoya por ver natural el respeto que Ombasi profesa hacia el cuerpo muerto de su amigo.

Si el comportamiento de Ombasi posiciona al público lejos de la familia, el proceder de ésta tiende a producir el mismo desenlace. Aunque la mayor parte de la película se centra en la insistencia de la familia en situarse como superiores a Ombasi basando su lógica en los mecanismos del racismo colonial, no logran covencer al espectador de su supuesta superioridad. Este énfasis en sentirse superiores se ve sobrepasado por la carencia de un conocimiento con fundamento y por una total ignorancia (activa y pasiva) del sujeto al que rechazan, todo unido a su incapacidad de demostrar la validez de los mecanismos que usan en su retórica. El hecho que los padres sean los transmisores de este tipo de discurso es muy significativo, ya que implica la transmisión del discurso racista colonial y con ello su supervivencia, al menos durante otra generación. Sin embargo, las bases en que asientan este discurso son muy débiles. Por una parte todos sus argumentos se basan en un conocimiento indirecto y pasivo, convirtiendo a Ombasi en un «otro» saidiano, un Oriente amenazante y atrayente que ansían poseer. Lo mismo ocurre con los conceptos, ideas y referencias sobre África que formulan basándolas en un conocimiento siempre indirecto. Además, no conocen nada de Ombasi, pues ni entienden su idioma ni intentan entenderlo, produciendo con esto último una ignorancia activa. De esta manera, en ningún momento basan su conocimiento en lo que saben de Ombasi ni profundizan en las bases de las referencias en las que fundamentan su percepción del inmigrante, lo que provoca que no cuestionen su comportamiento hacia él. El resultado es un listado de argumentos que sirven como base para un comportamiento que el espectador no puede aceptar, ya que carecen de fundamento y por consiguente provocan una imposibilidad de comprensión e identificación con la familia. Su ignorancia los hace a su vez objetos de su propia retórica, mediante la que se empeñan en definir al «otro» como aquel carente de cultura y conocimiento.

La falta de fundamento de sus argumentos se ve reforzada por una presentación directa y obvia de unos personajes simples e ignorantes que insisten en mostrarse como víctimas, dejándole el papel de culpable a Ombasi. Sin embargo, las palabras de Ombasi en español «iViva España! Indurain» muestran cómo es el país, y por extensión la familia, uno de los culpables de su situación. Por ejemplo, por medio de los comentarios y continuas quejas de los propios españoles sobre sus vidas, el público comprende que su situación en España no es muy buena. Sin embargo, cuando escuchan el «iViva España! Indurain» de Ombasi, se alegran. Estas palabras se refieren a una España de éxito a la que aparentemente ellos no tienen acceso, pero con la que se identifican en el momento de su encuentro con el extranjero. La situación nos transporta a la época colonial, cuando los sujetos colonizados tenían acceso a la metrópolis por medio de las palabras e imágenes que traían los colonizadores. Esto sigue ocurriendo en el presente y a semejanza de lo que sucedió en la época colonial, este «públi- 
co» sigue sin ser bienvenido. Aunque esta percepción de España no es el único motivo de la presencia de Ombasi, el país ha tenido un papel activo en la idea engañosa en la que se basa la esperanza de Ombasi. La familia confirma a su vez su rol como culpable al ratificar con su alegría e identificación ese «¡Viva España!» que minutos antes, al protestar sobre su situación laboral y familiar, parecía totalmente inviable. Si durante la película las acciones de Ombasi no lo presentan como un sujeto amenazante y peligroso, el comportamiento de la familia muestra, de manera indirecta, cómo Ombasi no es culpable sino una víctima del engaño que le ha traído hasta estas tierras poco acogedoras.

De hecho, la percepción de Ombasi como un ser amenazante contrasta con su permanente tranquilidad y pacifismo, hecho que choca con la agresividad que tanto los españoles como los neonazis muestran continuamente a lo largo de la película. Así, este comportamiento agresivo, tanto hablado como físico, junto con la continua carencia de fundamento de sus dictámenes sobre Ombasi, retrata a la familia como un grupo de salvajes sin cultura, como protagonistas de la propia retórica que habían intentado imponer a Ombasi. Por su parte, la buena disposición y conducta de Ombasi, junto con sus intentos de establecer un diálogo, lo alejan del tropo del animal y el salvaje, acercándolo más al ideal de sociedad europea y occidental que tienen los creadores del propio discurso racista, con lo que se invierte la mirada orientalista de la familia.

Si a lo largo de la película el espectador ha alternado entre la simpatía por la familia —dada su simpleza y en un principio inocencia- y el rechazo de su conducta, la última escena hace que el espectador se decante por este segundo sentimiento. Cuando el grupo de neonazis persigue a Ombasi para torturarlo, se le presenta a la familia una ocasión de redención. Al tiempo que ésta encuentra la bujía perdida y logra poner en marcha el coche para intentar escapar de los neonazis, Ombasi intenta huir de los mismos perseguidores. En este momento, la figura de Ombasi aparece corriendo desnuda por un camino rodeado de desierto, una imagen de desamparo que lo presenta con un sujeto sin nada que lo proteja y buscando a alguien que lo haga. Ombasi se dirige entonces hacia el coche de la familia y poco a poco vemos cómo se va acercando, hasta que aparece volcado sobre el capó. Su cara ocupa casi toda la pantalla, un primer plano que se repetirá varias veces durante esta escena. Ombasi busca con su mirada a los que están al otro lado del cristal, lo que podría percibirse como una mirada tanto hacia la familia que se encuentra al otro lado del parabrisas como hacia los espectadores, sentados al otro (y seguro) lado de la pantalla. Esta mirada tiene como respuesta un contraplano de Dori, que lo mira asustada y con lágrimas en sus ojos. Al no obtener la respuesta deseada de Dori, Ombasi rápidamente se coloca al otro lado del coche, junto al cristal del conductor. José Antonio intenta evitar la mirada de Ombasi, que aparece de nuevo en un primer plano mirando hacia el interior del coche, hacia la familia/público, y de nuevo el espectador se siente parte de la escena. La posición de la cámara dentro del vehículo coloca al público en el lado del español, y desde allí observa a Ombasi al otro lado del cristal (o de la pantalla). Seguidamente, el inmigrante se sitúa encima del capó, al otro lado del parabrisas frente a la madre. Tras este primer plano de Ombasi pidiendo ayuda, nos encontramos con otro primer contraplano de Dori diciendo: «¡Vete de aquí! ¿No lo entiendes? ¡Te van a matar! ¡Corre! ¡Corre! No puedo ayudarte. ¡No puedo! ¡No puedo!» El hecho de que los neonazis estén todavía lejos hace que nos cuestionemos las palabras de Dori. Su insitencia en « No puedo!» hace que el espectador se pregunte sobre el porqué de la reacción de Dori -ya que sí puede ayudarle, al contar con tiempo y espacio suficiente- y com- 
prenda que desde un primer momento Dori ha percibido a Ombasi como una «diferencia» imposible de aceptar. Es esa identidad basada en la diferencia la que le imposibilita prestar ayuda a Ombasi. Poco después, José Antonio hace un amago de ayuda, parando el coche y acercándose a Ombasi, aunque Dori lo convence rápidamente y se marchan. Este momento imposibilita definitivamente la identificación del espectador con el sujeto español. Durante la escena queda claro que no les hubiera costado ningún esfuerzo, ni les hubiera puesto en peligro, ayudar a Ombasi, ya que los neonazis estaban todavía a bastante distancia. Dori y José Antonio representan aquí un sentimiento común que tiende a producirse como consecuencia de la llegada de la inmigración a un país, una percepción del inmigrante como diferencia inadmisible. Esta diferencia se usa como justificación de la separación entre los dos sujetos, lo que provoca una indiferencia, aunque en el caso de Dori ocultada por las lágrimas, hacia ese sujeto considerado como opuesto (ya que esta separación imposibilita el establecimiento de toda posible relación entre los dos sujetos).

Según Eduardo Moyano, "[l]os tres [neonazis] son representantes del racismo centroeuropeo que es más beligerante e ideológico frente al racismo español que es más pasivo» (2005: 147). Aunque el racismo del grupo de neonazis es el más visible, Bwana ofrece a la familia la posibilidad de actuar, pero ésta actúa al no hacerlo. Tras la decisión de la familia de marcharse, alejándose de Ombasi dándole física y mentalmente la espalda, el público se queda con una imagen del inmigrante tendido en la carretera con una mano levantada en señal de petición de ayuda. En este momento el público se encuentra de nuevo frente al inmigrante, al igual que lo hizo cuando Ombasi intentaba encontrar una mirada amiga al otro lado del cristal. Ombasi le pide al espectador una respuesta, acción que se refuerza con su primer plano final que nos recuerda a Les 400 coups (1959), de François Truffaut, donde la imagen de Antoine, y en este caso la de Ombasi, queda congelada al cierre de la película. Esa mirada fija del inmigrante hacia el espectador convierte a este último en parte de la acción, animándole a establecer un diálogo con él.

El término «bwana» con el que Imanol Uribe decidió titular la película no es arbitrario. Imanol Uribe optó por transformar La mirada del hombre oscuro en Bwana, cambiando la perspectiva de la historia de Ignacio del Moral. En vez de enfocarse en «la mirada» de Ombasi, lo hizo en el comportamiento de «bwana», el sujeto blanco del discurso colonial que se convierte aquí en el objeto de estudio. Este sujeto, representado por la familia, se presenta como paradójico, ya que si por una parte se supone como el grupo con el que más se identificaría el público, por otra su comportamiento dificulta esta identificación. Así, al contrario de las películas de tema colonial en las que el colonizado era el objeto de la mirada del espectador, Bwana invierte esta mirada y coloca al español como objeto de estudio y espectáculo. Sin embargo, esto no lo hace a través de la mirada activa de Ombasi. La originalidad de Bwana reside en una transformación de «sujetos» a «objetos» de la familia española provocada por ella misma. De esta forma Bwana no reproduce el discurso colonial a la inversa, sino que lo cuestiona desde las mismas bases (o la falta de bases) desde las que se produce. Aparece así una sensación paradójica en el espectador; por una parte, existe la tendencia a identificarse con la familia por su identidad como miembros de su propio país; por otra, no hay posibilidad de empatía por el hecho de ser objetos de estudio.

Por otra parte, el encuentro entre el inmigrante y el espectador hace que este último reflexione sobre sí mismo, forzándolo a convertirse en un público activo. De forma paralela a la historia de Bwana, el público ha ido poco a poco perdiendo toda posibilidad de identificación 
con la familia, al mismo tiempo que lo que se presentó como una comedia fue convirtiéndose en tragedia. En palabras de Imanol Uribe: «creo que el mensaje final está en esa mirada del africano que es, como una mirada a todos nosotros. Y es que de verdad uno no puede hacer chistes de eso» (García, 1996). Bwana intenta así provocar una mirada hacia nuestro interior, un cuestionamiento de nuestra propia identidad e instintos. Cuando vamos a ver una película, nuestra intención es descubrir las vidas e historias de otras personas, penetrar en universos ajenos y compartir sus alegrías y tristezas. Sin embargo, como nos aconseja Maruja Torres, "No se la [Bwana] pierdan: hace reír, llorar y pensar». Bwana nos hacer pensar y reflexionar sobre lo que haríamos nosotros mismos ante esa situación.

Esta película no tiene como objetivo criticar a la familia en particular, sino llamar la atención sobre una gran mayoría de la sociedad española que no percibe al inmigrante como un igual. Esta sociedad se ha acostumbrado al llamado «drama de las pateras», y la tragedia del inmigrante se ha convertido en algo cotidiano que aparece a diario en los medios de comunicación cuya «normalidad» provoca indiferencia. Según Olga López Cotín,

En la creciente dislocación del orden social a medida que la violencia se apodera de la película, la traslación del epicentro de violencia de la familia —que es quien agrede a Ombasi en la obra- a traficantes y neonazis, grupos socialmente marginales, permite al espectador alinearse con la familia y reconocer que, si bien no es partícipe de las actitudes radicales xenofóbicas, sí es cómplice, en su desentendimiento e indiferencia. Aquí radica el elemento aleccionador de la película (2007: 153).

La última escena de Bwana pretende despertar la sensibilidad y la necesidad de tomar parte, de actuar de manera activa para que esa situación no se repita. El espectador se coloca como cómplice del desentendimiento de la familia española, aunque la película carece de elemento pedagógico. Bwana no nos ofrece un ejemplo de lo que hacer, sino un final dramático en el que el espectador queda cara a cara con Ombasi y con dos preguntas: ¿por qué la familia no ha ayudado a Ombasi? y ¿qué habría hecho yo en esa situación? Aunque han pasado quince años desde el estreno de Bwana, una gran parte del público de hoy en día sigue sin haber tenido contacto directo y cercano con immigrantes. La mirada de Ombasi causa que el público se pregunte sobre su reacción ante un encuentro posible en sus vidas, despertando en el espectador la curiosidad sobre un "otro» hasta ahora desconocido. Este "otro» no es solo el inmigrante que aparece casi a diario en los medios de comunicación pero que no conocen, sino también una identidad propia que todavía no había sido cuestionada, ese «otro» que vive dentro de «nosotros». 


\section{BIBLIOGRAFÍA}

AFRICANUS, Leo (1986), History and Description of Africa, and of the Notable Things Therein Contained, London, Hakluyt Society.

BALLESTEROS, Isolina (2001), Cine (ins)urgente: textos fílmicos y contextos culturales de la España posfranquista, Madrid, Fundamentos.

BARRENETXEA MARAÑÓN, Igor (2011), «El cine vasco, recopilación bibliográfica y documental» 2002. 8 agosto 2011 <http://www.fsancho-sabio.es/html/peliculas1.html>.

DEL MORAL, Ignacio (1992), La mirada del hombre oscuro, Madrid, SGAE.

FANON, Franz (1952), Peau noire, masques blancs, Paris, Éditions du Seuil.

GARCÍA, Rocío (2011), «Teníamos nuestros miedos antes del rodaje» 25 septiembre 1996. elpais.com. 8 agosto 2011 <http://www.elpais.com/articulo/cultura/URIBE /_IMANOL_/ CINEASTA/GUIPUZCOA/FESTIVAL_DE_SAN_SEBASTIAN/Teniamos/miedos/rodaje/ elpepicul/19960925elpepicul_1/Tes>.

JAHODA, Gustav (1999), Images of Savages: Ancient Roots of Modern Prejudice in Western Culture, New York, Routledge, 1999.

LÓPEZ COTÍN, Olga (2007), «Desde la mirada oscura: geografías fílmicas de la inmigración en España», en Rosalía Cornejo Parriego (ed.) (2007), Memoria colonial e inmigración: La negritud en la España posfranquista, Barcelona, Bellaterra, pp. 143-156.

MOYANO, Eduardo (2005), La memoria escondida: emigración y cine, Madrid, Tabla Rasa Libros y Ediciones.

PRATT, Mary Louise (1992), Imperial Eyes: Travel Writing and Transculturation, New York, Routledge.

SANTAOLALLA, Isabel (2005), Los «Otros»: Etnicidad, y «raza» en el cine español contemporáneo, Zaragoza, Prensas Universitarias de Zaragoza.

SHOHAT, Ella, y Robert STAM (1994), Unthinking Eurocentrism: Multiculturalism and the Media, New York, Routledge.

TORRES, Maruja (1996), «Bwana», 25 septiembre 1996. elpais.com. 8 agosto 2011 <http://www.elpais.com/articulo/ultima/uribe/ imanol/cineasta/Bwana/ elpepiult/19960925elpepiult 2/Tes>.

\section{FILMOGRAFÍA}

TRUFFAUT, François (1959), Les 400 coups, Interp. Jean-Pierre Léaud, Claire Maurier y Albert Rémy, Les Films du Carrossem.

URIBE, Imanol, Bwana (1996) Interp. María Barranco, Emilio Buale y Andrés Pajares, Aurum. 